$51-56$

\title{
A case of cervical metastases in a patient with preexisting cervical disc replacement and fusion after 2-year symptom-free interval: when do we need interdisciplinary diagnostics?
}

Authors Markus Melloh ${ }^{1}$, Thomas Barz²

Institutions ${ }^{1}$ Western Australian Institute for Medical Research, University of Western Australia

2 Department of Orthopaedic Surgery, Asklepios Klinikum Uckermark, Schwedt/Oder, Germany

\begin{abstract}
Recurrent cervical symptoms frequently occur after cervical disc replacement and fusion. To date, no algorithm for the diagnostic assessment of these symptoms has been established. We present a case report and review of the literature to illustrate the need for interdisciplinary diagnostics in recurrent cervicobrachialgia without pathological cervical imaging. The hospital chart, medical history, physical examination, and imaging of a single patient were reviewed. A 53-year-old man with preexisting cervical disc replacement and fusion presented with a new episode of cervicobrachialgia after a 2-year symptom-free interval. Cervical magnetic resonance imaging (MRI) showed no pathological findings. Six months later the patient reported increasing symptoms including numbness and weakness of the right arm. Repeated cervical MRI and thoracic computed tomography revealed cervical metastases with intraspinal tumor growth and an underlying extensive small cell bronchial carcinoma. In recurrent cervicobrachialgia, without pathological cervical imaging, interdisciplinary diagnostics are needed. Basic diagnostic tests may assist to exclude severe non-vertebrogenic pathologies.
\end{abstract}

The authors have no conflict of interest for this study. 


\section{INTRODUCTION}

Recent years have seen growing numbers of cervical disc replacements and fusions due to improved surgical techniques [1-3]. Diagnostics and differential diagnostics have been highly standardized [4]; however, recurrent cervical symptoms frequently occur [5]. Possible vertebrogenic causes lie within the treated or adjacent segments (Table 1) [6]. Primarily, local diagnostics of these causes are required (Table 2); yet, no algorithm for the diagnostic assessment of recurrent cervical symptoms has been established to date [7]. This bears the risk that non-vertebrogenic causes of cervical symptoms are diagnosed at a late stage.

Table 1 Causes of vertebrogenic symptoms after cervical disc replacement/fusion.

\begin{tabular}{l}
\hline Adjacent segment degeneration \\
\hline New or persisting central or foraminal stenosis \\
\hline Pseudarthrosis \\
\hline Vertebral fracture \\
\hline Cage/prosthesis migration \\
\hline Prosthesis loosening \\
\hline Facet joint degeneration \\
\hline Wear-induced granuloma \\
\hline Misalignment \\
\hline Nonphysiological load and movement patterns \\
\hline
\end{tabular}

Table 2 Local diagnostics for recurrent or persistent vertebrogenic symptoms after cervical disc replacement/fusion.

\begin{tabular}{l}
\hline Standard and oblique view $x$-ray \\
\hline Functional x-ray \\
\hline Computed tomography (CT) \\
\hline Myelography \\
\hline CT-myelography \\
\hline Magnetic resonance imaging (MRI) \\
\hline Contrast MRI \\
\hline Dynamic examination with image intensifier \\
\hline Scintigraphy \\
\hline Positron-emission tomography-CT \\
\hline Electroneurography/electromyography \\
\hline Somatosensory evoked potential test \\
\hline Magnetic evoked potential test \\
\hline Psychological exploration \\
\hline Facet joint and nerve root blocks \\
\hline Discography \\
\hline
\end{tabular}

\section{REPORT OF A CASE}

A 53-year-old nonsmoking man presented to our outpatient clinic with a new episode of cervicobrachialgia after a 2-year symptom-free interval. Two years ago, because of bilateral foraminal stenosis at $\mathrm{C} 5 / 6$ and $\mathrm{C} 6 / 7$ with increasing cervicobrachialgia, decompression and fusion at the severest level C5/6 (Pina Titan Cage $8 \mathrm{~mm} 14 \times 16 \mathrm{~mm}$ ) and disc replacement at C6/7 (Prodisc-C XL $8 \mathrm{~mm}$ ) had been performed due to different degenerative changes. In the preoperative routine check-up the patient had presented without a history of a malignant comorbidity. In the further course he had been symptom free. Routine cervical $\mathrm{x}$-ray had shown a stable fusion and a beginning kyphosis of the disc prosthesis (Fig $\mathbf{1}$ ). Two years after surgery the patient reported recurrent cervicobrachialgia; however, cervical magnetic resonance imaging (MRI) including STIR sequences showed no pathological findings except for incipient foraminal stenosis at levels $\mathrm{C} 3 / 4$ and $\mathrm{C} 4 / 5$ due to uncovertebral arthrosis (Fig 2). Therefore, no further imaging or invasive investigations such as computed tomography (CT)-myelography were indicated.

During the next 6 months his symptoms got worse with increasing numbness and weakness of the right arm. Repeated cervical MRI revealed bone metastases of the fourth and fifth vertebrae with intraspinal tumor growth (Fig $\mathbf{3}$ ). Thoracic $\mathrm{x}$-ray and CT demonstrated an extensive small cell bronchial carcinoma (Figs 4, 5). Beginning paraparesis required immediate treatment comprising debulking, radiotherapy as well as etoposide and cisplatin chemotherapy. Subsequent to deterioration of his general state of health, the patient died 2 weeks after the cancer diagnosis of cardiopulmonary decompensation.

Fig 1 (a) Postoperative cervical x-ray, lateral view.

(b) Postoperative cervical $x$-ray, anteroposterior view.

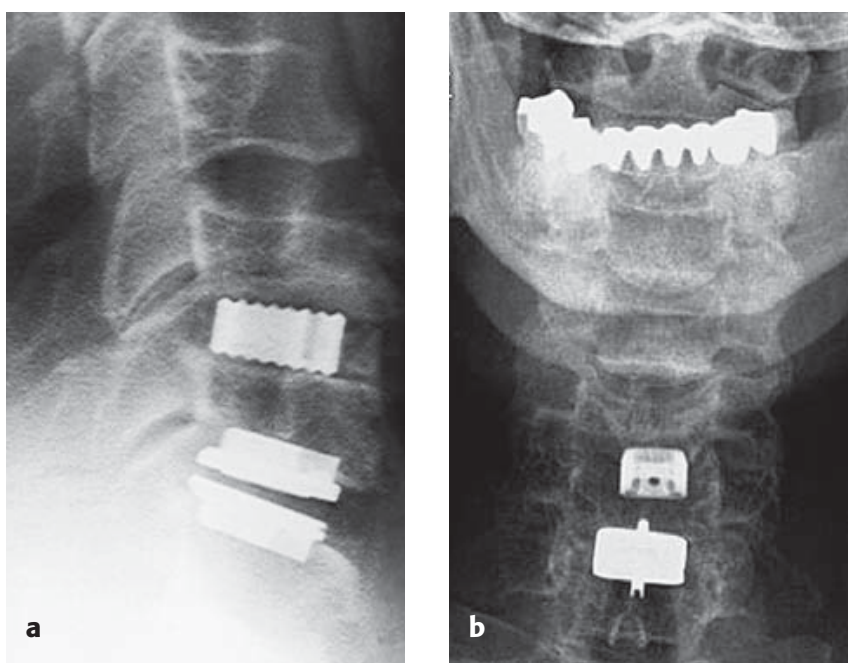




\section{DISCUSSION}

Good-to-excellent clinical results with a low complication rate are reported for ventral cervical fusion and disc replacement [8-10]. This applies likewise to disc replacement in combination with fusion [11, 12]. Yet, postoperative cervicobrachialgia is not uncommon [5, 13, 14]. Especially after a symptom-free interval of 2 years recurrent cervical symptoms are often believed to result from vertebrogenic causes. Metal artifacts complicate the evaluation of MRI and CT scans [15-17]. The absence of neurological deficits demands a nonsurgical treatment leading to a successful outcome in most patients [6]. However, recurrent cervicobrachialgia without pathological cervical imaging requires interdisciplinary diagnostics.
To our knowledge, there is only one report of a similar case in the literature. Pillai et al [18] presented the case of a patient developing metastases at the site of the arthroplasty 1 year after fusion at C3/4 to caution spine surgeons about the possibility that metastases might occur at the site of a cervical fusion and that a metastatic tumor should be accounted for in the differential diagnosis of recurrent cervicobrachialgia.

Potential nonvertebrogenic causes of cervicobrachialgia are given in Table 3. Basic diagnostic tests, such as thoracic $\mathrm{x}$-ray, erythrocyte sedimentation rate, C-reactive protein, and electrocardiogram may assist to exclude severe nonvertebrogenic pathologies. These tests are highly recommended in cases without pathological cervical imaging.
Fig 2 A 2-year postoperative cervical MRI, T2-weighted sagittal view.

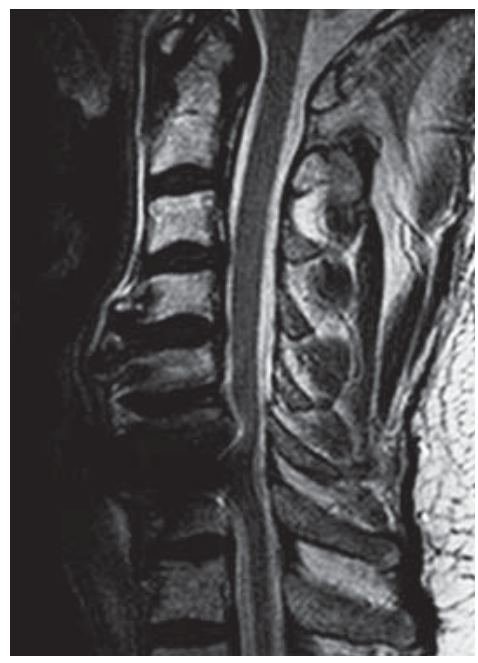

Fig 3 (a) A 2.5-year postoperative cervical MRI, T2-weighted sagittal view.

(b) A 2.5-year postoperative cervical MRI, T1-weighted axial view.
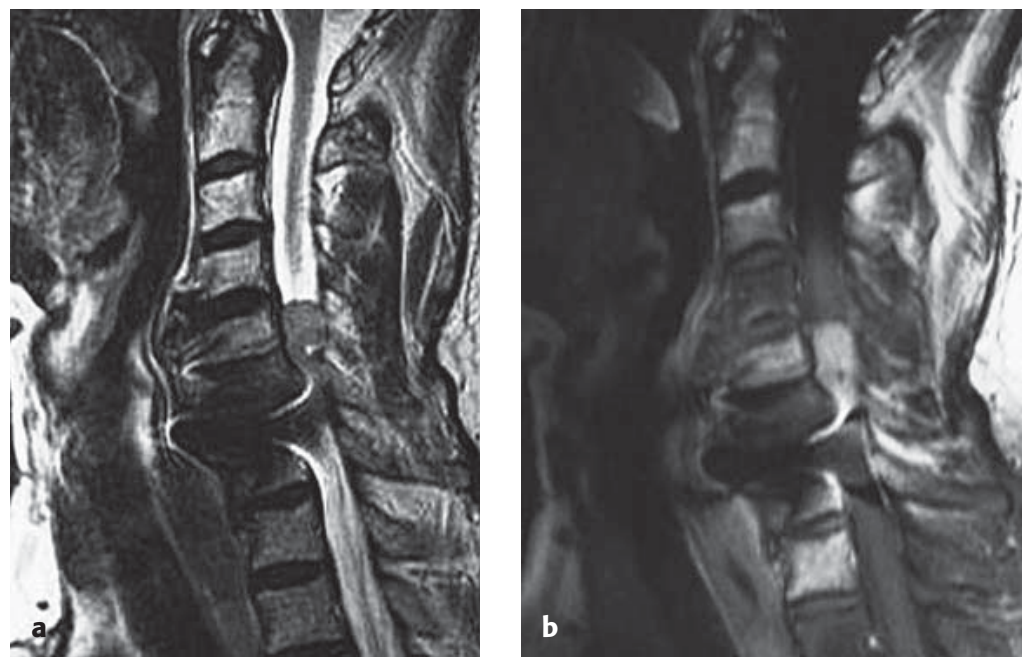

Fig 4 A 2.5-year postoperative thoracic $x$-ray, anteroposterior view.

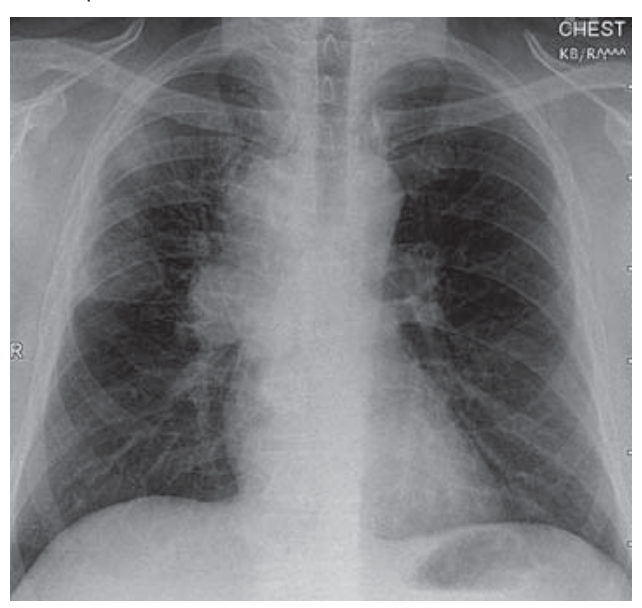

Fig 5 A 2.5-year postoperative thoracic $C T$, axial view.

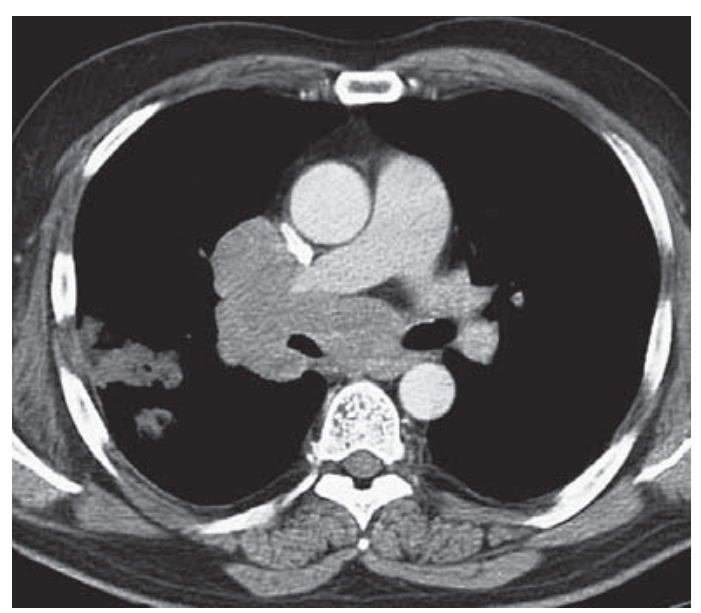


Table 3 Potential nonvertebrogenic causes of cervicobrachialgia.

\begin{tabular}{l}
\hline Migraine \\
\hline Herpes zoster \\
\hline Toothache \\
\hline Torticolli spasticus \\
\hline Oral and maxillofacial tumors \\
\hline Pancoast tumor \\
\hline Breast cancer \\
\hline Spastic esophagus \\
\hline Hiatus hernia \\
\hline Pneumothorax \\
\hline Pleuritis \\
\hline Pulmonary embolism \\
\hline Myocarditis \\
\hline Angina pectoris/myocardial infarction \\
\hline Aortic aneurysm \\
\hline Peripheral artery disease with ischemia \\
\hline Sudeck atrophy \\
\hline Carpal/radial/cubital tunnel, pronator teres, scalenus, thoracic outlet syndrome \\
\hline Epicondylitis humeri \\
\hline Serogenetic polyneuritis \\
\hline Basilar impression and similar skeletal deformities \\
\hline Neuralgic shoulder amyotrophy \\
\hline Shoulder impingement syndrome/omarthritis/omarthrosis. \\
\hline Polymyalgia rheumatica \\
\hline Neurotic disorders \\
\hline
\end{tabular}

\section{CONCLUSION}

This case illustrates the need for interdisciplinary diagnostics in recurrent cervicobrachialgia without pathological cervical imaging. Basic diagnostic tests may assist to exclude severe nonvertebrogenic pathologies.

\section{REFERENCES}

1. Le H, Thongtrangan I, Kim DH (2004) Historical review of cervical arthroplasty. Neurosurg Focus; 17(3):E1.

2. McAfee PC (2004) The indications for lumbar and cervical disc replacement. Spine J; 4(Suppl 6):177S-181S.

3. Suchomel P, Jurak L, Benes V 3rd, et al (2010) Clinical results and development of heterotopic ossification in total cervical disc replacement during a 4-year follow-up. Eur Spine J; 19(2):307-315.

4. Korinth MC (2008) Treatment of cervical degenerative disc disease: current status and trends. Zentralbl Neurochir; 69(3):113-124.

5. Pickett GE, Sekhon LH, Sears WR, et al (2006) Complications with cervical arthroplasty. J Neurosurg Spine; 4(2):98-105.

6. Denaro V, Papalia R, Denaro L, et al (2009) Cervical spinal disc replacement. J Bone Joint Surg Br; 91(6):713-719.

7. Bartels RH, Beems T, Schutte PJ, et al (2010) The rationale of postoperative radiographs after cervical anterior discectomy with standalone cage for radicular pain. J Neurosurg Spine; 12(3):275-279.

8. Bertagnoli R, Duggal N, Pickett GE, et al (2005) Cervical total disc replacement, part two: clinical results. Orthop Clin North Am; 36(3):355-362.

9. Mummaneni PV, Burkus JK, Haid RW, et al (2007) Clinical and radiographic analysis of cervical disc arthroplasty compared with allograft fusion: a randomized controlled clinical trial. J Neurosurg Spine; 6(3):198-209.

10. Murrey $D$, Janssen $M$, Delamarter $R$, et al (2009) Results of the prospective, randomized, controlled multicenter Food and Drug Administration investigational device exemption study of the ProDisc-C total disc replacement versus anterior discectomy and fusion for the treatment of 1-level symptomatic cervical disc disease. Spine J; 9(4):275-286. 
11. Barbagallo GM, Assietti R, Corbino L, et al (2009) Early results and review of the literature of a novel hybrid surgical technique combining cervical arthrodesis and disc arthroplasty for treating multilevel degenerative disc disease: opposite or complementary techniques? Eur Spine J; 18(Suppl 1):29-39.

12. Shin DA, Yi S, Yoon do H, et al (2009) Artificial disc replacement combined with fusion versus two-level fusion in cervical two-level disc disease. Spine (Phila Pa 1976); 34(11):1153-1159; discussion 1160-1161.

13. Shinomiya K, Okamoto A, Kamikozuru M, et al (1993) An analysis of failures in primary cervical anterior spinal cord decompression and fusion. J Spinal Disord; 6(4):277-288.

14. Yoon DH, Yi S, Shin HC, et al (2006) Clinical and radiological results following cervical arthroplasty. Acta Neurochir (Wien); 148(9):943-950.

15. Lee IS, Kim HJ, Choi BK, et al (2007) A pragmatic protocol for reduction in the metal artifact and radiation dose in multislice computed tomography of the spine: cadaveric evaluation after cervical pedicle screw placement. J Comput Assist Tomogr; 31(4):635-641.

16. Sekhon LH, Duggal N, Lynch JJ, et al (2007) Magnetic resonance imaging clarity of the Bryan, Prodisc-C, Prestige LP, and PCM cervical arthroplasty devices. Spine (Phila Pa 1976); 32(6):673-680.

17. Tominaga T, Shimizu H, Koshu K, et al (1995) Magnetic resonance imaging of titanium anterior cervical spine plating systems. Neurosurgery; 36(5):951-955.

18. Pillai P, Mendel E, Ray-Chaudhury $A$, et al (2010) Metastasis development at the site of cervical spine arthrodesis. Acta Neurochir (Wien); 152(3):509-513.

\section{EDITORIAL PERSPECTIVE}

The EBSJ editors thank the authors for sharing this important case with the readership.

There are three important learning points here:

- "Not everything that looks like a horse is a zebra." However, just because disc degeneration is so very common should not mean that we operate on all patients with cervical imaging abnormalities. The principle of evaluating a patient clinically and then connecting clinical findings with insights gained by imaging remains the time-honored principle of spinal management for a good reason. For patients with neck/arm symptoms a differential diagnosis of other pathoentities, such as primary shoulder problems, compressive neuropathies, brachial plexus lesions, radiculitis or Parsonage-Turner syndrome and in rare cases malignancy (Pancoast tumor!) or infection are important considerations to keep in mind. The use of electrodiagnostic tests, such as electromyography, is frequently shunned in this era of painless advanced imaging but is essential to differentiate a radiculopathy from a brachial neuritis and a compressive neuropathy.

- Symptom recurrence after spine surgery: Melloh and Barz correctly point out that symptom recurrence after neural decompression surgery is not uncommon and is multifactorial. A structured approach toward symptom recurrence is indeed helpful. The EBSJ editors recommend the methodical five-step approach suggested by the late Henry Bohlman:

1. Was the index surgery done for the right reason in the right patient at the right time?

2. Was the surgery done well?

3. Has everything healed well?

4. Has something new occurred, such as recurrent stenosis, breakdown above or below, infection, neoplasia, neurodegenerative disorder, metabolic disease, and so on?

5. Has the patient remained with the prescribed conditioning program?

- Imaging after disc arthroplasty: This remains largely unstructured. The commentary by John G DeVine might help settle some of the rampant misperceptions, especially regarding use of MRI following arthroplasty and invite a more systematic approach to be formulated. 


\section{COMMENTARY}

John G DeVine, $M D$

Department of Orthopaedic Surgery

Eisenhower Army Medical Center

Ft Gordon, GA, USA

Melloh and Barz describe an interesting case of recurrent cervicobrachialgia after a 2-year symptom-free period. The patient had undergone a two-level anterior cervical discectomy with a fusion at the C5/6 level and an arthroplasty at the C6/7 level. The initial work-up included cervical $x$-rays and magnetic resonance imaging (MRI) including STIR sequences that revealed no obvious pathological findings. No further imaging was obtained at that time. As his symptoms progressed over the next 6 months, a repeated cervical MRI was obtained revealing metastatic lesions of the fourth and fifth cervical vertebrae with extension of the tumor into the canal. Eventual diagnosis was made after thoracic computed tomography (CT) revealed the origin of the metastasis to be small cell bronchial carcinoma.

This case is unique in that the etiology of the recurrent cervicobrachialgia was metastasis. The authors point out that there is only one other reported case in the literature [1]. However, this is not an uncommon clinical scenario. In addition to a medical history and physical examination, first-line imaging should include x-ray evaluation and MRI. The clarity of MRI after cervical arthroplasty has been reported. Titanium devices allow for satisfactory imaging of the adjacent and index levels, but non-titanium devices (cobalt-chrome-molybdenum alloys) create significant image distortion, preventing accurate imaging at the index and adjacent levels [2]. More recently, it has been demonstrated that magnet strength affects the artifact from cobalt-chrome alloys. Using a lower strength magnet, such as the 0.2 Tesla magnet found in many of the open scanners, the reduction in artifact allows for adjacent segment imaging without a significant reduction in quality [3]. However, the index levels are still significantly distorted.
In cases when symptoms persist without an obvious explanation using MRI-myelography followed by CT-myelogram is the imaging modality of choice. The image distortion can be minimized, while allowing better visualization of the vertebral morphology, and earlier detection of trabecular destruction in the case of metastasis. Additionally, the presence of neural compression can be appreciated centrally and in the proximal nerve roots at every level, including the index level after arthroplasty.

Last, other imaging modalities can be used to detect the presence of occult metastasis in the setting of disc arthroplasty when the index of suspicion is high on the differential, or if there is already a diagnosis of malignancy and staging is required. Technetium$99 \mathrm{~m}$ bone scan is useful to identify areas of amplified metabolic activity and has a high sensitivity for detecting lesions. Positron emission tomography uses fluorodeoxyglucose to define sites of increased metabolic activity and is more sensitive and specific in detecting bone metastasis.

As Melloh and Barz make clear, in cases when no obvious pathology is identified in the initial MRI in patients presenting with recurrent symptoms after disc arthroplasty, interdisciplinary diagnostics may be required. In addition to basic diagnostic tests, such as erythrocyte sedimentation rate and C-reactive protein, $x$-rays and electrocardiogram, I would also recommend CT-myelogram in the setting of a preexisting disc arthroplasty.

1. Pillai P, Mendel E, Ray-Chaudhury A, et al (2010) Metastasis development at the site of cervical spine arthrodesis. Acta Neurochir (Wien); 152(3):509-513.

2. Sekhon LH, Duggal N, Lynch JJ, et al (2007) Magnetic resonance imaging clarity of the Bryan, Prodisc-C, Prestige LP, and PCm cervical arthroplasty devices. Spine (Phila Pa 1976); 32(6):673-680.

3. Antosh IJ, DeVine JG, Carpenter CT, et al (2010) Magnetic resonance imaging evaluation of adjacent segments after cervical disc arthroplasty: magnet strength and its effect on image quality. J Neurosurg Spine; 13(6):722-726. 